\title{
PENERAPAN TEKNIK BERMAIN KARTU PINTAR UNTUK MENINGKATKAN MOTIVASI BELAJAR DAN HASIL BELAJAR IPA
}

\author{
Bambang Surahmadi \\ SMP N 1 Temanggung \\ Email: adibambang88@yahoo.com
}

\begin{abstract}
This study aims to determine the application of smart card-playing techniques to improve learning motivation and learning outcomes of science learners. The medium used is a smart card, a card which contains information contained in the subject matter learning objectives are packaged in the form of questions and answers. The research was conducted in SMP Negeri 1 Temanggung learners of class VIII G in 2nd semester Academic Year 2014/2015. The method used is a Class Action Research. Data collection methods used were questionnaires, pre-test and post-test. The research data in the form of learning outcomes IPA concept of test and motivation to learn is obtained from the questionnaire motivation. Statistical analysis showed in the first cycle an average yield is 56,67of pretest increased to an average is 70,58of posttes; the second cycle average is 62,24of pretest increased to an average is 80,86of posttest and third cycle average is 70,26 of pretest increased to an average is 84,24 of posttest While the motivation of learners increased by $86 \%$ from the priortreated. Based on the results of the research, processing and data analysis and hypothesis testing measures taken in this study, we concluded that the application of smart card play technique can enhance learning motivation and learning outcomes of class VIIIG students of SMP Negeri 1 Temanggung.
\end{abstract}

Keywords: smart card, learning motivation, learning outcomes.

\section{PENDAHULUAN}

Pendidikan IPA merupakan salah satu cabang ilmu pengetahuan yang mengajarkan berbagai pengetahuan yang dapat mengembangkan daya nalar, analisis, hingga hampir semua persoalan yang berkaitan dengan alam dapat dimengerti. Diantara mata pelajaran lainya mata pelajaran IPA selama ini dianggap sulit oleh peserta didik, sehingga kurang bersemanggat dan kurang termotivasi dalam menerima pelajaran. Hal ini menyebabkan peserta didik tidak bergairah menerima pelajaran dan 
Bambang Surahmadi -Penerapan Teknik Bermain...

proses belajar mengajar tidak berjalan lancar sehingga keadaan tidak kondusif dan interaktif serta cenderung pasif pada akhirnya prestasi belajar peserta didik tidak sesuai yang diharapkan.

Umumnya dalam membelajarkan IPA kepada peserta didik di SMP N 1 Temanggung guru masih menggunakan paradigma pembelajaran lama dalam arti kondisi dalam pembelajaran cenderung berlangsung monoton dan satu arah dari guru ke peserta didik. Guru sangat mendominasi pembelajaran sehingga pembelajaran cenderung membosankan dan mengakibatkan peserta didik merasa jenuh dan bosan. Oleh karena itu dalam membelajarkan IPA kepada peserta didik, guru hendaknya lebih memilih berbagai variasi pendekatan, model, maupun strategi yang sesuai dengan situasi dan kondisi sehingga tujuan pembelajaran yang direncanakan akan tercapai.

SMP N 1 Temanggung merupakan salah satu sekolah favorit di kota tersebut, tetapi jika dilihat rata-rata nilai IPA masih kurang dari nilai KKM. Masih ada beberapa peserta didik yang belum tuntas KKM. Ini dikarenakan pembelajaran yang dilakukan kurang memotivasi peserta didik.

Oleh sebab itu perlu adanya upaya guru yang dapat membuat dan mengunakan media serta menciptakan suasana belajar yang, aktif, inovatif, kreatif, efektif dan menyenangkan dalam proses pembelajarannya.

Menurut Aqib (2013), media pembelajaran adalah perantara, pengantar, atau segala sesuatu yang dapat digunakan untuk menyalurkan pesan dan merangsang terjadinya proses belajar pada peserta didik. Media pembelajaran yang digunakan harus menarik perhatian siswa, sehingga mampu meningkatkan minat belajar siswa.Selain membangkitkan motivasi dan minat siswa, media pembelajaran juga dapat membantu siswa meningkatkan pemahaman (Arsyad, 2011).

Media yang dapat digunakan untuk meningkatkan daya ingat dan konsep peserta didik bisa menggunakan "Kartu Pintar". Melalui kartu ini, peserta akan lebih mudah mengasah daya ingatnya terhadap materi karena kartu ini berisi ringkasan informasi materi pelajaran yang terdapat dalam 
tujuan pembelajaran yang dikemas dalam bentuk pertanyaan dan jawaban. Kartu ini dibuat semirip mungkin dengan kartu permainan yang dimodifikasi dengan gambargambar atau alat yang sering dijumpai dalam pembelajaran.

Istilah penerapan memiliki makna suatu implementsi dari suatu alat yang digunakan untuk mencapai program yang diharapkan, sedangkan teknik adalah suatu metode atau strategi untuk mencapai tujuan tertentu. Bermain disini suatu cara yang digunakan sebagai rangsangan agar kegiatan menjadi menarik perhatian dan menjadi suatu permainan yang menyenangkan, saling berlomba untuk mendapatkan skor yang tinggi. Sehingga peserta didik lebih mudah untuk diarahkan untuk mencapai tujuan pembelajaran.

Istilah motivasi berasal dari kata motif yang dapat diartikan sebagai kekuatan yang terdapat dalam diri individu, yang menyebabkan individu tersebut bertindak atau berbuat (Uno, 2014). Motivasi menjelaskan apayang membuat orang melakukan sesuatu, membuat mereka tetapmelakukannya, dan membantu mereka dalam menyelesaikan

tugastugas.Sedangkan menurut Santrock (2014) motivasi merupakan proses yang memberikan energi, mengarahkan, dan mempertahankan perilaku.

Ada dua faktor yang dapat mempengaruhi motivasi belajar peserta didik yaitu faktor intrinsik dan ekstrinsik, faktor intrinsik adalah hal dan keadaan yang berasal dari pribadi peserta didik itu sendiri yang dapat mendorong melakukan kegiatan belajar. Sedangkan faktor ekstrinsik adalah hal dan keadaan yang datang dari luar individu peserta didik yang juga mendorong peserta didik melakukan kegiatan belajar.

Menurut Sudjana (2013) penilaian atau hasil belajar merupakan suatu proses usaha yang dilakukan seseorang dimaksudkan untuk mengetahui tercapai dan tidaknya tujuan-tujuan yang telah ditetapkan, tetapi juga untuk mengetahui apakah tujuan-tujuan tersebut penting bagi siswa dan bagaimana siswa mencapainya

Sistem tata surya merupakan materi IPA yang berhubungan dengan alam semesta. Materi ini memiliki 
daya tarik tersendiri bagi peserta didik karena berhubungan dengan alam dan kehidupan sehari-hari. Untuk itu diperlukan suatu media untuk mempermudah memahami materi tersebut. Maka dalam penelitian ini akan digunakan suatu media berupa kartu pintar.

Penelitian yang dilakukan oleh Mursalina (2014) tentang keefektifan kartu pintar pengetahuan terhadap aktivitas dan hasil belajar struktur bumi menjelaskan bahwa media kartu pintar pengetahuan efektif digunakan dalam pembelajaran IPA materi struktur bumi di kelas V MI Walisongo Kranji 02.

Tujuan dari penelitian ini adalah untuk mengetahui penerapan teknik bermain kartu pintar untuk meningkatkan motivasi belajar dan hasil belajar IPA peserta didik kelas VIII G SMP N 1 Temanggung tahun ajaran 2014/2015.

\section{METODE}

Penelitian ini merupakan Penelitian Tindakan Kelas (PTK), sebagai upaya untuk memperbaiki dan meningkatkan mutu pembelajaran. Pada model penelitian ini terdapat 4 komponen yang meliputi perenungan untuk menentukan masalah, perencanaan (planning), tindakan (acting), observasi (observing) dan refleksi (reflecting).

Perencanaan (planning), sebelum mengadakan penelitian peneliti menyusun rumusan masalah, tujuan dan membuat rencana tindakan, termasuk di dalamnya instrumen penelitian dan perangkat pembelajaran.

Melaksanakan tindakan (acting), pada tahap ini observer melaksanakan tindakan yang telah dirumuskan pada RPP dalam situasi yang aktual.

Melaksanakan pengamatan (observing) . Pada tahap ini, yang harus dilakukan observer adalah; mengamati perilaku siswa dalam mengikuti KBM, memantau kegiatan diskusi antar siswa dalam kelompok, mengamati pemaham tiap siswa terhadap penguasaan materi pembelajaran yang telah dirancang Melakukan refleksi (reflecting). Pada tahap ini observer harus; mencatat hasil observasi, mengevaluasi hasil observasi, menganalisis hasil pembelajaran, mencatat isi hasil 
Bambang Surahmadi-Penerapan Teknik Bermain ...

pembelajaran, mencatat kelemahan untuk dijadikan bahan penyusunan rancangan siklus berikutnya. Model penelitian tindakan kelas dapat dilihat pada gambar 1 .

Subjek dalam penelitian tindakan kelas ini adalah peserta didik kelas
VIIIG SMP Negeri 1 Temanggung dengan jumlah peserta didik sebanyak 32 orang yang terdiri dari 14 orang peserta didik laki-laki dan 18 orang peserta didik perempuan.

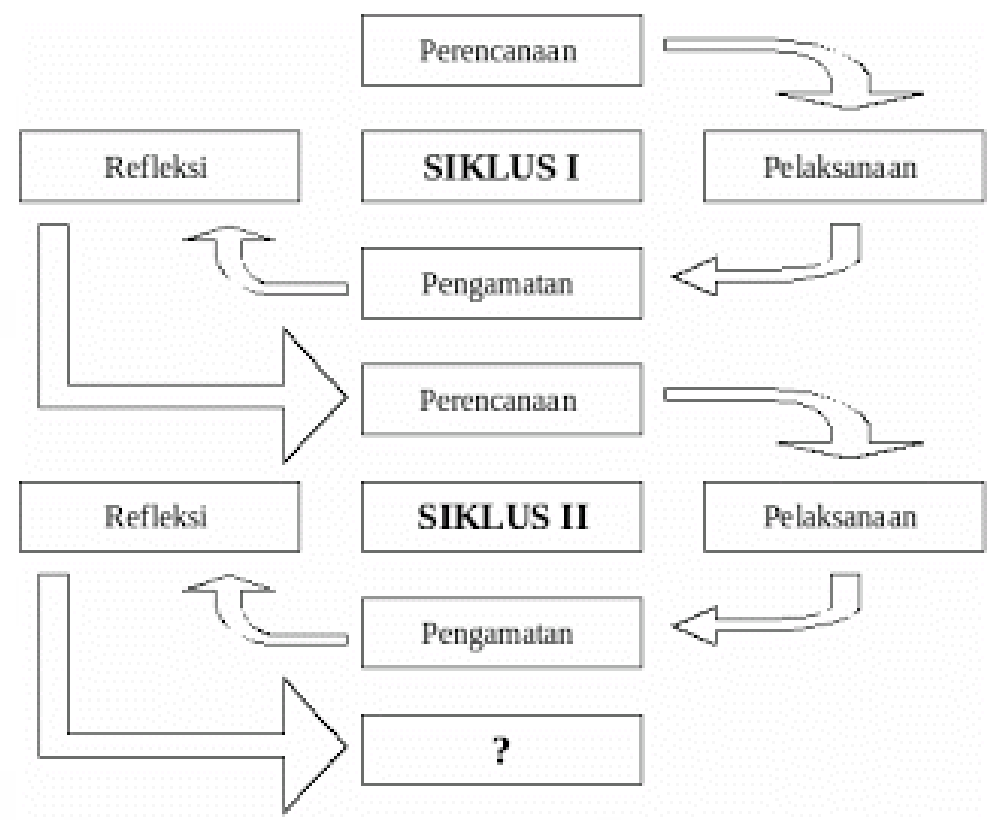

Gambar 1. Model Penelitian Tindakan Kelas (Arikunto: 2010)

Data pemahaman konsep peserta didik yang meliputi data pretest dan postest diambil untuk mengetahui perkembangan kemajuan pembelajaran peserta didik dan data ini juga digunakan untuk mengetahui tingkat pemahaman hasil belajar peserta didik. Ketuntasan peserta didik dalam belajar apabila peserta didik dapat memperoleh nilai pretes dan posttest $\geq 80$.

Sedangkan untuk mengetahui nilai motivasi peserta didik dianalisis dengan cara menjumlahkan skor total angket yang diisi peserta didik dibagi skor maksimum dikali 100. 


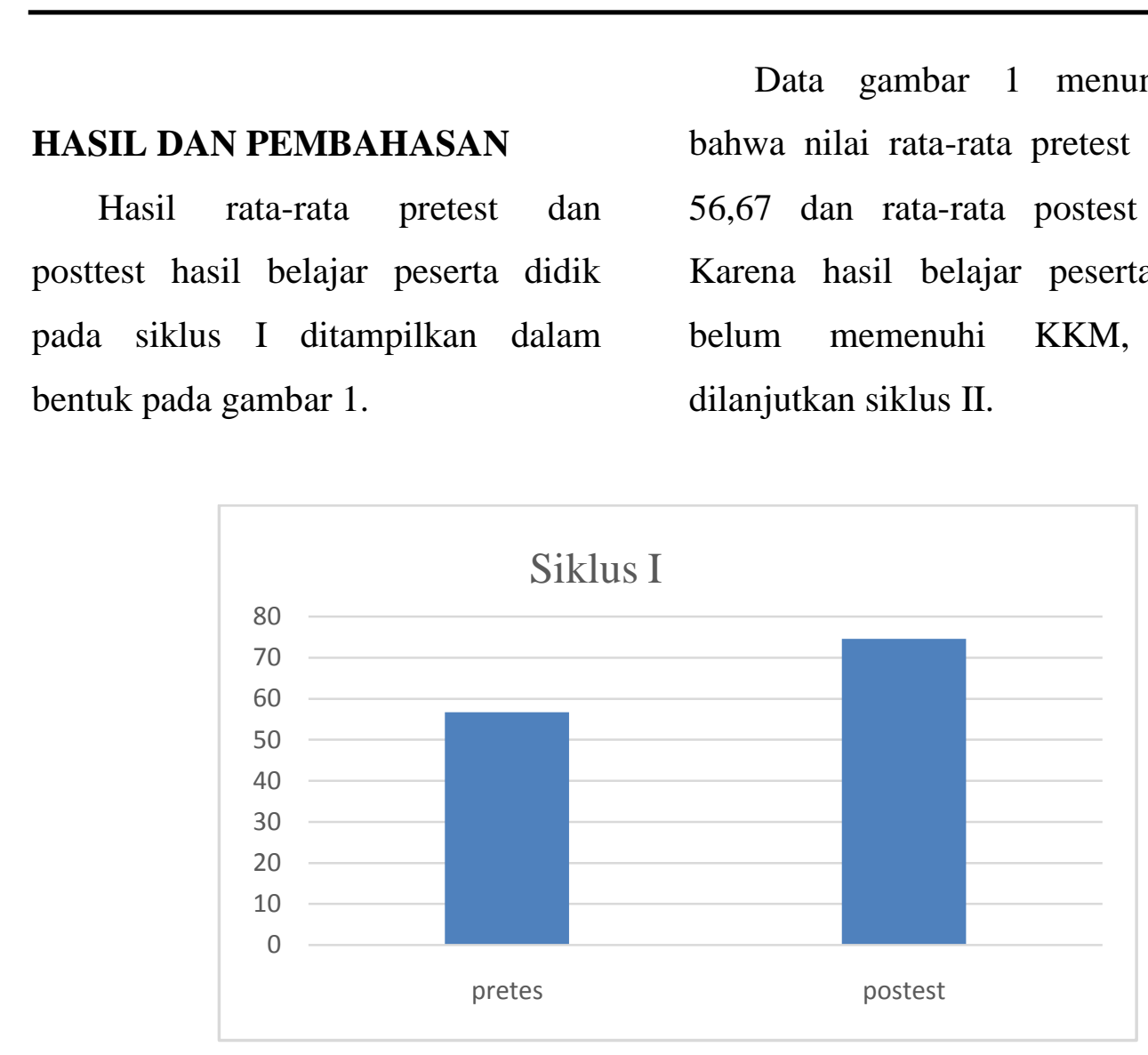

Gambar 1. Grafik pretest dan posttest peserta didik pada siklus I

Hasil pretest dan posttest hasil belajar peserta didik pada siklus II ditampilkan dalam bentuk grafik berikut:

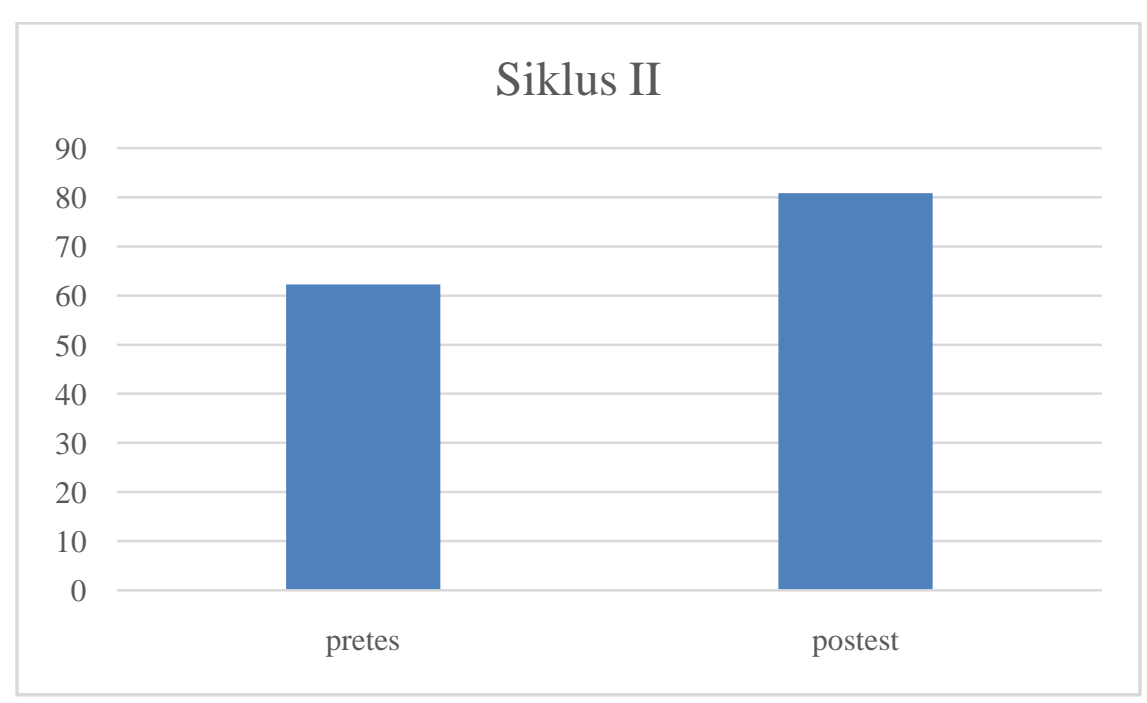

Gambar 2. Grafik pretest dan posttest peserta didik pada siklus II 
Data gambar 2 menunjukkan bahwa nilai rata-rata pretest sebesar 62,24 dan rata-rata postest 80,86 . Dari data tersebut dapat dilihat terjadi peningkatan hasil belajar peserta didik. Hasil rata-rata pretest dan posttest hasil belajar peserta didik pada siklus III ditampilkan dalam bentuk grafik pada gambar 3 .
Data gambar 3 menunjukkan bahwa nilai rata-rata pretest sebesar 70,26 dan rata-rata postest 84,24. Dari data tersebut dapat dilihat terjadi peningkatan hasil belajar peserta didik dan sudah melampaui KKM.

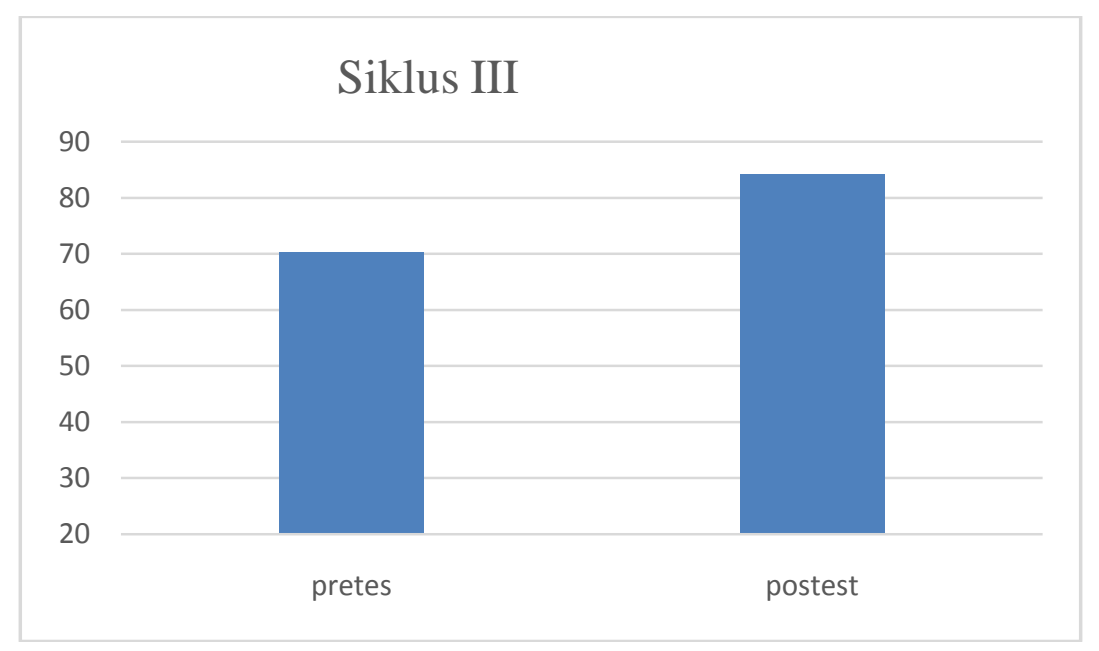

Gambar 3. Grafik pretest dan posttest peserta didik pada siklus III

Dari hasil penelitian diperoleh data hasil motivasi belajar peserta didik dari tiap siklus mengalami peningkatan. Pada siklus I terdapat 4 peserta didik yang memiliki motivasi tinggi, 10 peserta didik memiliki motivasi sedang, dan 18 peserta didik termotivasi rendah. Kemudian pada siklus II terdapat 10 peserta didik yang memiliki motivasi tinggi, 14 peserta didik memiliki motivasi sedang, dan 8 peserta didik termotivasi rendah. Dan pada siklus III terjadi peningkatan motivasi belajar yang signifikan. Terdapat 25 peserta didik yang memiliki motivasi tinggi dan 7 peserta didik memiliki 
motivasi sedang. Dapat dikatakan bahwa motivasi belajar peserta didik meningkat $86 \%$ dari sebelum diberi perlakuan. Jadi, dalam menentukan strategi maupun media dalam pembelajaran sangat menentukan aktivitas peserta didik. Jika media pembelajaran yang diberikan peserta didik sesuai maka peserta didik akan termotivasi tinggi dalam belajar di kelas.

Hasil belajar peserta didik pada siklus I, siklus II, dan siklus III mengalami peningkatan yang baik. Terjadinya peningkatan rata-rata hasil belajar peserta didik ini menunjukkan bahwa penelitian tindakan kelas dengan menerapkan teknik bermain kartu pintar yang dilakukan memiliki hasil yang baik, sehingga dapat membantu dalam mengatasi permasalahan yang terjadi di kelas.

\section{PENUTUP}

\section{Kesimpulan}

Berdasarkan analisis dari data yang diperoleh, maka dapat disimpulkan bahwa penerapan teknik bermain kartu pintar dapat meningkatkan motivasi belajar dan hasil belajar peserta didik kelas VIIIG SMP Negeri 1 Temanggung.

\section{Saran}

Dalam upaya meningkatkan keberhasilan proses pembelajaran hendaknya guru mencari penyebab permasalahan di kelas kemudian mencari solusi penyelesaiannya dan senantiasa melakukan penelitian untuk meningkatkan kemampuan profesional guru. Untuk peneliti selanjutnya yang akan menggunakan kartu pintar sebagai media pembelajaran hendaknya disesuaikan dengan materi yang cocok dan tepat.

\section{DAFTAR PUSTAKA}

Aqib, Zaenal. 2013. Model-model, Media, dan Strategi Pemmbelajaran Kontekstual (Inovatif). Bandung: Yrama Widya.

Arikunto, Suharsimi., dkk. Penelitian Tindakan Kelas, (Jakarta: Bumi Aksara, 2010),

Arsyad, Azhar. 2011. Media Pembelajaran. Jakarta: Rajagrafindo.

Mursalina, Dina. 2014. Keefektifan Kartu Pintar PengetahuanTerhadap Aktivitas Dan Hasil Belajar Struktur Bumi. Journal of Elementary Education. ISSN 2252-9047. Universitas Negeri Semarang. 
Santrock, John W. 2014. Psikologi

Pendidikan. Jakarta: Salemba

Humanika.

Sudjana, Nana. 2013. PenilaianHasil

Proses BelajarMengajar.

Bandung: RemajaRosdakarya

Uno, Hamzah B. 2014. Teori Motivasi

dan Pengukurannya. Jakarta:

BumiAksara. 